\title{
ARTICLE
}

\section{Positive Egalitarianism Reconsidered}

\author{
Gustaf Arrhenius (D) and Julia Mosquera (1) \\ Institute for Futures Studies (IFFS), Stockholm \\ Gustaf.Arrhenius@iffs.se \\ Julia.Mosquera@iffs.se
}

(Received 17 April 2019; revised 13 November 2019; accepted 14 November 2019)

\begin{abstract}
According to positive egalitarianism, not only do relations of inequality have negative value, as negative egalitarians claim, but relations of equality also have positive value. The egalitarian value of a population is a function of both pairwise relations of inequality (negative) and pairwise relations of equality (positive). Positive and negative egalitarianism diverge, especially in different-number cases. Hence, an investigation of positive egalitarianism might shed new light on the vexed topic of population ethics and our duties to future generations. We shall here, in light of some recent criticism, further develop the idea of giving positive value to equal relations.
\end{abstract}

\section{Introduction}

The topic under discussion here, following in the tracks of Larry Temkin's influential work on inequality, is how to rank populations with regard to their egalitarian value, that is, how populations can be ordered by the relation 'is at least as good as with respect to egalitarian concerns. ${ }^{1}$ One should distinguish this undertaking from the project of how such a ranking would play into the all things considered rankings of populations, where we also have to consider other aspects, such as the total welfare in a population, and from the project of ranking populations in terms of the primarily descriptive relation 'is at least as (un)equal as.'. Another way of putting it is that we are asking what our well-informed preference from a moral perspective would be if we only cared about inequality and equality (of some sorts). ${ }^{3}$

Several authors, for example Larry Temkin, Ingmar Persson, and Shlomi Segall, have argued in favour of the view that inequality among people is bad, that is, it detracts from

Gustaf Arrhenius and Julia Mosquera contributed equally to this work.

${ }^{1}$ Cf. Arrhenius (2009), (2013); Temkin (1993). For simplicity, we are here only considering human populations but the framework could easily be extended to include other sentient beings.

${ }^{2}$ We say 'primarily' since this relation might be partly evaluative because the currency might involve an evaluation. For example, to say that Tim has higher welfare than Orri in outcome X is an evaluation to the effect that Tim is better off than Orri in X. For the same point, see Rabinowicz (2003), fn. 7.

${ }^{3}$ See Arrhenius (2013) for a more detailed discussion of this topic.

(c) The Author(s), 2021. Published by Cambridge University Press. This is an Open Access article, distributed under the terms of the Creative Commons Attribution licence (http://creativecommons.org/licenses/by/4.0/), which permits unrestricted re-use, distribution, and reproduction in any medium, provided the original work is properly cited. 
the egalitarian value of a population, whereas equality among people is neither good nor bad but of neutral value, that is, equality among people neither adds nor detracts from the egalitarian value of a population. ${ }^{4}$ It is fair to say that this is the received view on the value of inequality and equality. Arrhenius (2013) formulated a version of this view with more content: ${ }^{5}$

Negative egalitarianism: The egalitarian value of a population is a strictly decreasing function of pairwise relations of inequality.

Negative egalitarianism can be contrasted with a novel view that, in addition to the negative value of unequal relations, also ascribes positive value to relations of equality, as suggested by Kawchuk (1996a), Arrhenius (2013), and Mosquera (2017b). We shall refer to this position as positive egalitarianism:

Positive egalitarianism: The egalitarian value of a population is a strictly decreasing function of pairwise relations of inequality and a strictly increasing function of pairwise relations of equality. ${ }^{6}$

Let's us expand on what these two positions involve. They presuppose a currency of egalitarian justice, which is a contested subject. ${ }^{7}$ For simplicity, let's assume that the egalitarian currency is welfare (or, to put it differently, 'welfare' is a place-holder for whatever is the correct currency of egalitarian justice) and that individual welfare is measured on an interpersonally comparable ratio scale. Moreover, again for simplicity, let the measure of pairwise relations of inequality be the absolute value of the difference in welfare between the two involved individuals. ${ }^{8}$

Consider a population A consisting of three persons, $p_{1}, p_{2}, p_{3}$, with welfare 10,20 , and 20 respectively. We can represent this as $A=\langle 10,20,20\rangle$. According to negative egalitarianism, the egalitarian value of $\mathrm{A}$ is a function of the absolute value of the welfare differences of all distinct pairs of different individuals in $\mathrm{A}$, that is, $\left(p_{1}, p_{2}\right),\left(p_{1}, p_{3}\right)$, and $\left(p_{2}, p_{3}\right){ }^{9}$ In this case, there are two pairwise relations of inequality of size 10 between $p_{1}$ and $p_{2}$, and $p_{1}$ and $p_{3}$ respectively, which are of negative value.

\footnotetext{
${ }^{4}$ Persson (2001), p. 30, holds the same view: 'According to this conception [of egalitarianism], the intrinsic value of just equality will be neutral, consisting in the mere absence of something intrinsically bad, namely unjust inequality'. Larry Temkin's position seems to be similar. Although Temkin doesn't explicitly address the question of whether equality has positive value, he provides a number of arguments for why the mere addition of equally well-off people doesn't improve a population from the point of view of equality, but rather worsens it, since such addition can increase the inequality in a population in various different respects. See for example Temkin (1993), pp. 23, 211. See also Segall (2016), pp. 74-86.

${ }^{5}$ See Arrhenius (2013). Negative egalitarianism wasn't separately stated in Arrhenius's paper, but it makes up the 'inequality part' of his definition of positive egalitarianism (p. 85).

${ }^{6}$ Arrhenius (2013).

${ }^{7}$ For this debate, see e.g. Rawls (1971); Sen (1980), (1992b), (1993); Dworkin (1981a), (1981b), (2000); Cohen (1989), (1993); Arneson (1989), and Nielsen (1996).

${ }^{8}$ One might also reasonably make this measure more sophisticated to take into account that, for instance, differences at low levels matter more than differences at high levels (by, for example, transforming the individual welfare levels with a strictly increasing concave function). There are other more sophisticated functions that could be used but since this won't be relevant for the discussion below, we shall leave this issue aside here.

${ }^{9}$ Hence, it's not a function of the identity pairs, e.g. $\left(p_{1}, p_{1}\right)$, and each pair of distinctive individuals are only counted once, e.g. $\left(p_{1}, p_{2}\right)$ and $\left(p_{2}, p_{1}\right)$ is counted as one pair.
} 
According to positive egalitarianism, the egalitarian value of A isn't only a function of the two inequalities of size 10 but also of the equality between $p_{2}$ and $p_{3}$, which is of positive value.

The idea of giving positive value to equal relations is analogous to how the value of desert has been conceptualised. If someone deserves a certain amount of some good, it is not only bad that the person receives much less than what she deserves, it is also good that she receives what she deserves. ${ }^{10}$ Moreover, people usually don't have a neutral attitude to equality, which would be fitting if equality only had neutral value as implied by negative egalitarianism, but a pro-attitude, which can be taken as evidence for the idea that equality has a positive value. ${ }^{11}$

Negative and positive egalitarianism can diverge in both same- and differentnumber cases. An example of a same-number case is that negative egalitarianism will always ascribe negative egalitarian value to populations like $\mathrm{A}$, whereas some version of positive egalitarianism might ascribe positive egalitarian value to such populations, for example, when the involved inequality is so small that its negative value is outweighed by the positive value of the equal relation. As we shall see, however, these views come apart even more in different-number cases. Moreover, these views are substantial positions that rule out some positions regarding the value of equality (more on this below).

There are at least three good reasons to consider egalitarian aspects of population change in different-number cases. Firstly, doing so might shed new light on the vexed topic of population ethics and our duties to future generations, since equality is one aspect in the ranking of future populations of different sizes. Secondly, if we want to measure the value of equality and inequality over time, we have to take into account that the size of the compared populations might have changed. For example, when one tries to measure the development of global equality and inequality during the last thirty years or so, one has to take into account the great population expansion in countries such as India and China. ${ }^{12}$ Moreover, climate change is very likely to affect not only future people's welfare but also the size of future populations. ${ }^{13}$ Thirdly, this new dimension of egalitarian theory is a fruitful way of probing our ideas about egalitarian concerns and reveals yet under-discussed and surprising complexities and problems in our current conceptualisation of the value of equality, as the discussion above indicates.

\section{Mere addition of better-off people}

Let us first consider a different-number case from Arrhenius (2013):

In figure 1, the height of the vertical lines and of the rectangle represent people's welfare according to some suitable measure or proxy. Each vertical line represents

\footnotetext{
${ }^{10}$ See, e.g. Feldman (1995a), (1995b), (1997); Arrhenius (2003a), (2006), (2007).

${ }^{11}$ For further discussion of the evidential value of pro-attitudes, see Oddie (2005). See also the discussion of J. S. Mill's suggested proof of utilitarianism as discussed by Crisp (1997), pp. 75-77). In his proof, Mill makes a connection between desiring happiness and the desirability of happiness. His argument assumes, or so Crisp argues, that pro-attitudes (or seemings) towards an object count as evidence for the goodness of that object.

${ }^{12}$ See, e.g. Bosmans, Decancq, \& Decoster (2014) for some important results in this area.

${ }^{13}$ For a discussion of the relationship between climate change and demography, see Bommier, Lanz, \& Zuber (2015); Carleton et al. (2019); Geruso \& Spears (2018); Hales, Kovats, Lloyd, \& Campbell-Lendrum (2014); Mejean, Pottier, Zuber, \& Fleurbaey (2017).
} 
Figure 1. Mere additions of better-off people.

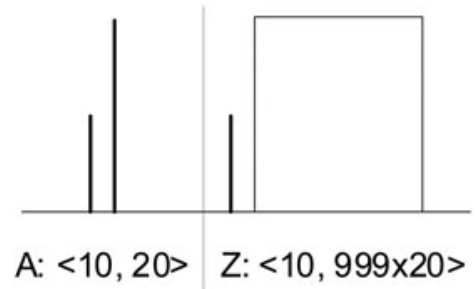

one individual whereas the rectangle represents a group, the size of which is indicated by the width of the rectangle. All the lives in figure 1 have positive welfare, or, as we could also put it, have lives worth living, which is represented by positive numbers. ${ }^{14}$ Population A consists of two persons, one with half of the welfare of the other, 10 and 20 units respectively. In Z, we have added another 998 best-off people with 20 units of welfare. $^{15}$

Intuitively, many would judge $\mathrm{Z}$ to be better than $\mathrm{A}$ with respect to egalitarian concerns since $\mathrm{Z}$ is very close to perfect equality whereas $\mathrm{A}$, on the other hand, is a straightforwardly unequal population. This is also what several standard measures of inequality imply, as we shall see below.

One way of rationalising this intuitive judgment in a more precise manner is this: in $\mathrm{A}$, there are no relations of equality but one relation of inequality. In $\mathrm{Z}$, on the other hand, there are a staggering 498,501 relations of equality, which in comparison outweigh the puny 999 relations of inequality. ${ }^{16}$ Hence, one might reasonably judge $\mathrm{Z}$ as better than $\mathrm{A}$ in regard to egalitarian concerns, and a natural way to account for this intuition is to claim that from an egalitarian perspective, we should not only care about relations of inequality but also about relations of equality, as suggested by positive egalitarianism. ${ }^{17}$

Notice that it doesn't follow from positive egalitarianism that $\mathrm{Z}$ is better than $\mathrm{A}$ in respect of egalitarian concerns since it is compatible with any ranking of these populations. The ranking depends on what weight we give to the great increase in equal relations as compared to the relatively small increase in unequal relations. Interestingly, that $\mathrm{Z}$ is better than $\mathrm{A}$ in regard to egalitarian concern is implied by the Gini coefficient (and some other standard measures, for example, relative

\footnotetext{
${ }^{14}$ For a discussion of alternative definitions of a neutral life, many of which would also work fine in the present context, see Arrhenius (forthcoming), chs 2 and 9; Arrhenius (2000b). See also Broome (1999), (2004), and Parfit (1984), pp. 357-58, and appendix G).

${ }^{15}$ A structurally similar case involves mere additions of worse off people (see Arrhenius (2013), pp. 7576; Arrhenius (2019); Parfit (1984), p. 425). Instead of Z, we could consider $Z$ ': $<20,999 \times 10>$. Much of what we say about the comparison between $\mathrm{A}$ and $\mathrm{Z}$ in the text also holds for the comparison between $A$ and $Z^{\prime}$. For example, the Gini coefficient ranks $Z^{\prime}$ as better than $A$ in regard to egalitarian concerns.

${ }^{16}$ Since the number of pairwise relations in a population of size $n$ is $1 / 2 n(n-1)$, we obtain the result that the number of equal relations in $\mathrm{Z}$ is $999(999-1) / 2=498501$.

${ }^{17}$ Another way of rationalising this intuition is to consider how much welfare each better-off individual has to transfer to the worst-off individual for the population to reach perfect equality. In A, the best-off individual has to sacrifice a lot more than what the more numerous best-off individuals in $\mathrm{Z}$ have to sacrifice.
} 
mean deviation). ${ }^{18}$ The Gini coefficient is approximately 0.17 for A and only 0.0005 for $\mathrm{Z}^{19}$

Negative egalitarianism, on the other hand, implies that $\mathrm{Z}$ is worse than $\mathrm{A}$ with regard to inequality since in the change from $A$ to $Z$, the number of unequal relations increases from 1 to 999 , and the size of the gaps are the same. ${ }^{20}$ This shows, interestingly, that the Gini coefficient is ruled out by negative egalitarianism. The reason is that Gini not only takes into account the number of unequal pairs, but is also sensitive to the number of equal pairs in a population since they figure in the denominator. Hence, Gini isn't, as one might believe, a measure that only gives weight to unequal relations, but it rather belongs to the family of positive egalitarian theories that also give weight to equal relations. ${ }^{21}$

Segall (2016) has considered this case and disagrees with the judgement explained above of positive egalitarians and others who rank $\mathrm{Z}$ as better than $\mathrm{A}$ in regard to egalitarian concerns:

In A there are two individuals living in inequality. But in $\mathrm{Z}$ the sense of inequality of that one worse off person is magnified (almost) a thousand times. And the fact that there are 999 better-off individuals living in equality amongst themselves does not detract from that badness, and potentially even emphasises her isolation as a worse-off individual in that society. ${ }^{22}$

However, positive egalitarianism doesn't claim that the '999 better-off individuals living in equality amongst themselves . . . detract from ... [the] badness' of the inequality between the person with welfare 10 and the people with welfare 20 . On the contrary, positive egalitarianism implies that $\mathrm{Z}$ is worse in one respect that is relevant for egalitarian concerns, namely in respect to the number of unequal relations to which the

\footnotetext{
${ }^{18}$ See Kawchuk (1996b: 159), Arrhenius (2013), (2016) for a discussion of such measures. One might also be interested in Average per pair inequality (APPI): the sum of the absolute value of all welfare differences for all distinct pairs of individuals in the population divided by the number of such pairs (see Rabinowicz (2003) and Arrhenius (2013)). APPI also ranks $\mathrm{Z}$ as better than A with respect to inequality since $A P P I(A)=(|10-20|) / 2(2-1) / 2=10$ whereas $A P P I(Z)=(999|10-20|) /\left(1000^{*} 999\right) / 2=0.02$. A measure proposed by Derek Parfit is likely to have the same implication. Parfit compares two populations, A+ and Alpha. A+ consists of two groups of people of the same size, one with 100 units of welfare per person, and one with 50 units of welfare per person. Alpha consists of one group of the same size as A+ but with 105 units of welfare per person and a very large group of people with 45 units of welfare per person. He writes: 'The inequality in Alpha is in one way worse than the inequality in A+, since the gap between the better-off and the worse-off people is slightly greater. But in another way the inequality is less bad. This is a matter of the relative numbers of, or the ratio between, those who are better-off and those who are worse-off. Half of the people in $\mathrm{A}+$ are better off than the other half. This is a worse inequality than a situation in which almost everyone is equally well off, and those who are better off are only a fraction of one per cent. . . . All things considered, the natural inequality in Alpha is not worse than the natural inequality in A+' (Parfit (1986), p. 156).

${ }^{19}$ The Gini coefficient is defined as $\frac{1}{2 n^{2} \hat{y}} \sum_{i=1}^{n} \sum_{j=1}^{n}\left|y_{i}-y_{j}\right|$.

${ }^{20}$ Likewise according to Temkin's Individual complaint theory (Temkin (1993), ch. 2), since the worstoff person has many more complaints in $\mathrm{Z}$ as compared to in $\mathrm{A}, 999$ complaints versus 1 .

${ }^{21}$ Strictly speaking, Gini is ruled out by positive egalitarianism as we have defined it above since adding equal relations to a perfectly equal population won't increase the egalitarian value according to Gini (it will be the same) whereas this follows from positive egalitarianism. Gini is, however, compatible with a weaker version of positive egalitarianism according to which the egalitarian value of a population is a decreasing function of pairwise relations of inequality and an increasing function of pairwise relations of equality.

${ }^{22}$ Segall (2016), p. 76.
} 
worst-off person is subject. It is just that positive egalitarians also value equal relations, and since there are so many of them in $\mathrm{Z}$, this may outweigh the badness of the unequal relations when it comes to egalitarian concerns. Again, in A, there are no relations of equality and one relation of inequality, whereas in $Z$ there is a staggering 498,501 relations of equality, which in comparison outweigh the few 999 relations of inequality.

Secondly, let us again stress that it doesn't follow from positive egalitarianism that $\mathrm{Z}$ is better than A in respect to egalitarian concerns, but it is compatible with that judgement. It depends on what weight we give to the increase in unequal relations as compared to the increase in equal relations. Hence, Positive egalitarians could accommodate Segall's intuition by changing the relative weight of the value of equal and unequal relations. To make Segall's claim into an effective argument against positive egalitarianism, one would have to show that there are no cases of the type depicted in figure 1, that is, cases in which the positive value of an increase in equal relations outweighs the negative value of a much smaller increase in unequal relations, possibly involving very small inequalities (e.g. consider a version of the case in figure 1 where $A=\langle 19,20\rangle$ and $\mathrm{Z}=<19,999 \times 20>$ ). This is a rather tall order, we surmise, since it is tantamount to showing that irrespective of how small the inequalities are and how many more equal relations there are, the positive value of the equal relations cannot outweigh the negative value of the unequal relations.

A further issue is the 'isolation' of the worst-off individual that Segall appeals to in the previous quote. This point can be understood in different ways. It could be taken as a psychological claim regarding the welfare of the worst-off individual: that she suffers from being the only worst-off person. Taken this way, the objection misses its target since any effects on the welfare of the person are already taken into account in figure 1 and the worst-off has the same welfare in both outcomes.

More interestingly, Segall hints at the putative badness of the isolation of a single worse off individual in a society, in the quote above. This can be a further aspect to take into account when we rank $\mathrm{A}$ and $\mathrm{Z}$ with respect to egalitarian concerns. Mosquera (2017a) has a more developed proposal that also takes account of this intuition. Her idea is that the way in which relations of inequality are distributed should also matter when accounting for the egalitarian value of a population. It is for example pro tanto worse if the inequalities are concentrated on a single worse off individual rather than on many worse off individuals. Mosquera refers to this as 'Distribution-sensitive pairwise egalitarianism'. Going back to the case with $\mathrm{A}$ and $\mathrm{Z}$, there are more relations of inequality concentrated on the worse off individual in $Z$, as compared to A. In this respect, $\mathrm{Z}$ is worse than $\mathrm{A}$.

However, the question is what weight should be assigned to those considerations as compared to other egalitarian considerations. Mosquera doesn't commit to any particular weighing and would not claim that her account implies that $\mathrm{Z}$ is worse than $\mathrm{A}$, taking into account all the relevant egalitarian concerns. It is indeed possible for an egalitarian to assign such an extremely high weight to the putative badness of the 'isolation' of a single worse-off individual in a society, such that the ranking of $\mathrm{A}$ and $\mathrm{Z}$ in respect to egalitarian concerns would be reversed as compared to the ranking provided by positive egalitarianism and Gini. But it is hard to find a convincing argument for such a radical view, we surmise.

To sum up, we think that Segall's ranking of $\mathrm{A}$ and $\mathrm{Z}$ is partly based on an equivocation of inequality and egalitarian concerns. Furthermore, it overlooks the great number of equal relations in $\mathrm{Z}$ as compared to the small number of unequal relations. It is this difference that makes it intuitively attractive to rank $\mathrm{Z}$ as better than $\mathrm{A}$ in respect of 
egalitarian concerns and along the lines of reasonable versions of positive egalitarianism and other theories such as the Gini coefficient. The appeal to 'isolation' or 'concentration' seems insufficient to reverse the ranking in this case.

\section{The progression case}

As we showed above, negative and positive egalitarianism come apart in different-number cases. But as we also mentioned in the introduction, negative and positive egalitarianism can also diverge in same-number cases. In fact, Segall suggests another criticism against positive egalitarianism that is based on a same-number case where he claims that positive egalitarianism yields the wrong result. It might be instructive to look at it now. Consider the following two same-sized populations of 1,000 people each:

In figure 2, the numbers above the height of the vertical lines and the rectangle represent people's welfare. The number of people at each welfare level is indicated by the numbers below the neutral welfare line.

Segall claims that $\mathrm{Z}^{\prime}$ is better than $\mathrm{Z}$ with regard to egalitarian concerns:

My intuition is that $Z^{\prime}$ is better than $Z$ with respect to equality. This is so even though $Z^{\prime}$ contains many more incidents of inequality, and no relations of equality at all. ${ }^{23}$

Positive egalitarianism of course yields the opposite ranking. One might get the impression from Segall's discussion that what makes $Z$ better than $Z^{\prime}$ according to positive egalitarianism is the fact that $Z$ contains a lot of relations of equality, while $Z^{\prime}$ has no relations of equality. As we shall show below, this is wrong, since negative egalitarianism also ranks $\mathrm{Z}$ as better than $\mathrm{Z}^{\prime}$ in respect of egalitarian considerations. Positive egalitarianism gives extra reasons for this ranking because of the positive value of the relations of equality in $Z$, but it is not the main reason for why $Z$ is better than $Z^{\prime}$.

It might not be evident that both negative and positive egalitarianism imply that $Z^{\prime}$ is worse than $\mathrm{Z}$ with respect to equality so let us informally demonstrate it. We can do a one-to-one mapping of all the 999 unequal pairs in $Z$ to a corresponding unequal pair in $Z^{\prime}$ with a greater gap. According to negative egalitarianism, this subset of unequal pairs from $Z^{\prime}$ will be worse with respect to equality than the set of unequal pairs from $Z$. Since all the pairs in $Z^{\prime}$ that remain unmapped after this are unequal, this will only further decrease the egalitarian value of $Z^{\prime}$. The same demonstration holds for positive egalitarianism since the equal relations in $\mathrm{Z}$ will increase the egalitarian value of $\mathrm{Z}$ further, as compared to the egalitarian value of $\mathrm{Z}^{\prime}$.

Here is a figure illustrating the same point:

In figure 3, the two ellipses denoted $\operatorname{pr}(Z)$ and $\operatorname{pr}\left(Z^{\prime}\right)$ represent the set of all pairwise relations of equality and inequality in populations $Z$ and $Z^{\prime}$ respectively. Relations of equality are represented by ' $=$ ' whereas relations of inequality are represented by ' $\neq$ '. The horizontal arrows from $\operatorname{pr}(\mathrm{Z})$ to $\operatorname{pr}\left(\mathrm{Z}^{\prime}\right)$ represent the mapping of all the relations of inequality from $\operatorname{pr}(\mathrm{Z})$ to relations of inequality of greater size in $\operatorname{pr}\left(\mathrm{Z}^{\prime}\right)$. Hence, the circle in $\operatorname{pr}(Z)$ represents the set of all relations of inequality in $\operatorname{pr}(Z)$ whereas the circle in $\operatorname{pr}\left(Z^{\prime}\right)$ represents some subset containing relations of inequality in $\operatorname{pr}\left(Z^{\prime}\right)$ of size greater than 49 . The latter subset will be worse with respect to equality than the former according to negative egalitarianism. As figure 3 shows, all the pairs in $\operatorname{pr}\left(\mathrm{Z}^{\prime}\right)$ that

\footnotetext{
${ }^{23}$ Segall (2016), p. 76.
} 


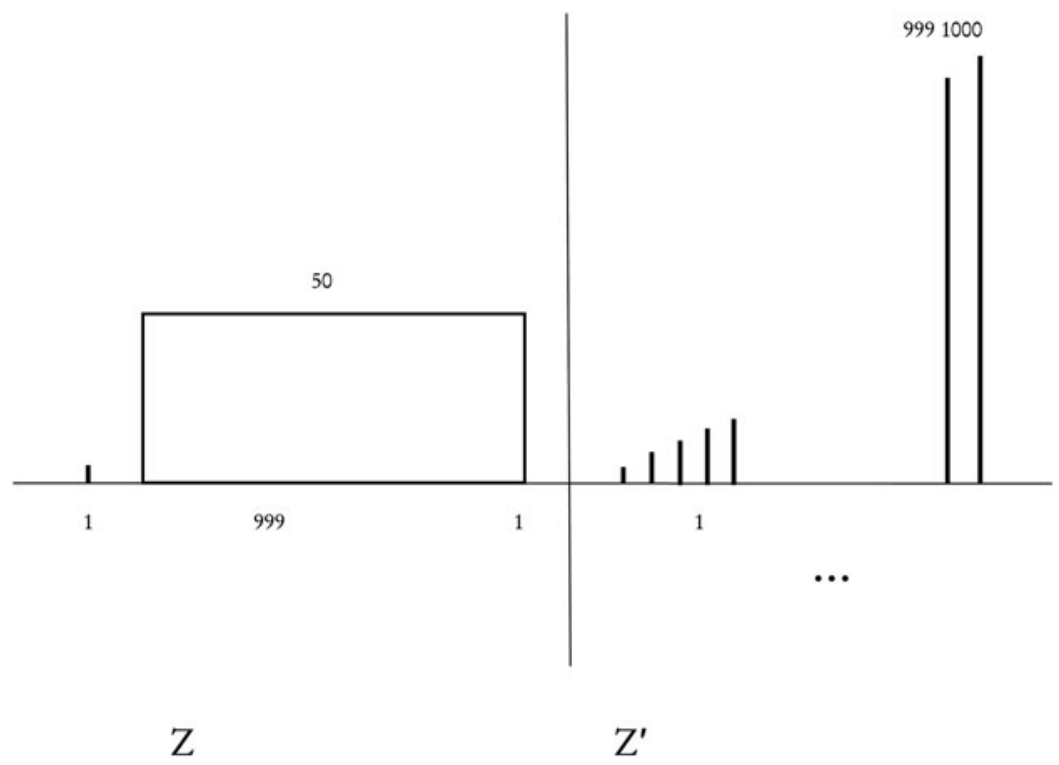

Figure 2. The progression case.

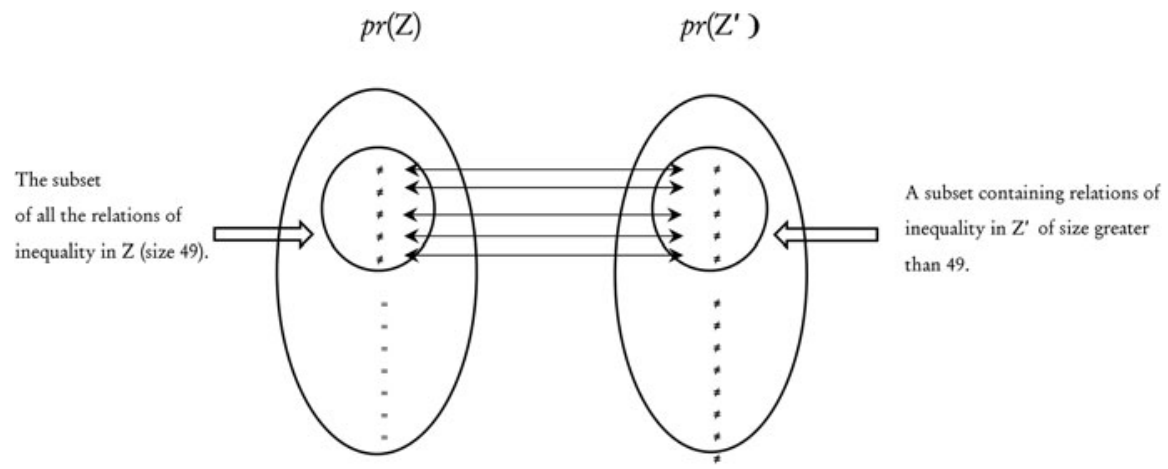

Figure 3. A one-to-one mapping of the unequal relations in $Z$ to unequal relations of greater size in $Z^{\prime}$

remain unmapped are unequal, and thus will further decrease the egalitarian value of $Z^{\prime}$. Moreover, all the unmapped pairs in $\operatorname{pr}(Z)$ are equal and thus will increase the egalitarian value of $Z$ further as compared to the egalitarian value of $Z^{\prime}$.

Does Segall's case show that we have to reject both positive and negative egalitarianism? We don't think so. Segall's ranking of $Z$ and $Z^{\prime}$ overlooks the great magnitude of the inequalities in $Z^{\prime}$. Firstly, as Segall concedes, population $Z^{\prime}$ contains a greater number of relations of inequality than $\mathrm{Z}^{24}$ However, it is important to notice how much

\footnotetext{
${ }^{24}$ The formula for calculating the number of pairwise relations in a population of size $\mathrm{N}$ is $\mathrm{N}(\mathrm{N}-1) / 2$. In the case of $Z^{\prime}$, where there are no equal relations, the number of unequal relations coincide with the total number of pairwise relations in the population as defined above. In the case of a population with both
} 
greater the number of such relations is in $\mathrm{Z}^{\prime}$ as compared to $\mathrm{Z}$. As Mosquera has pointed out, the latter population contains only 999 relations of inequality of size 49 whereas $Z^{\prime}$ contains as many as 499,500 relations of inequality of sizes ranging from 1 to $999 .^{25}$

Secondly, the vast majority of the relations of inequality in $\mathrm{Z}^{\prime}$ involve a bigger gap than the inequalities in $Z$. In $Z^{\prime}, 450,775$ relations out of a total of 499,500 relations of inequality are of size greater than 50 . In $\mathrm{Z}$, on the other hand, the relatively puny 999 relations of inequality are all of size smaller than $50 .^{26}$

As an illustration only of the magnitude of the inequality contained in $Z^{\prime}$, consider individual 1 in $Z^{\prime}$ who is subject to 949 relations of inequality greater than 49 . As pointed out by Mosquera, these 949 relations of inequality range from size 50 to size 999, whereas, again, the relations of inequality in $\mathrm{Z}$ are of size $49 .^{27}$

Hence, there are many more and greater inequalities in $Z^{\prime}$ as compared to $Z$. Thus, pace Segall, it makes eminent sense for an egalitarian to rank $Z^{\prime}$ as worse than $Z$ in respect of egalitarian concerns.

Finally, let us here take the opportunity to point out a simple misunderstanding of positive egalitarianism on Segall's part. He writes:

A major difference [between Segall's and positive egalitarianism's verdicts on $\mathrm{Z}$ and $Z^{\prime}$ ] of course is that Arrhenius's positive egalitarianism simply counts the number of incidents of both equality and inequality but does not take into consideration the magnitude of the latter. ${ }^{28}$

Positive egalitarianism, however, does take into account the size of the inequalities in the distribution since it is an extension of negative egalitarianism. The set of all pairs of individual welfare levels in a population contains information about the size of the gaps and the number of unequal pairs. Negative and positive egalitarianism take into account both of these aspects so that the greater the gap, and the more of such unequal relations, the worse in regard to egalitarian concerns. This is rather clear from Arrhenius' original paper in which there is extensive discussion on how to take into account the size of inequalities, but also on how to weigh them against the positive value of equal relations. ${ }^{29}$ For example, he writes that 'it seems appropriate that both the number and the size of inequalities matter'. ${ }^{30}$

More importantly, negative and positive egalitarianism, as defined above, rule out egalitarian views according to which the egalitarian value of a population sometimes isn't affected by an increase in the gaps or by an increase in the number of unequal pairs. A simple example is the Range measure where the egalitarian value only

unequal and equal relations, the number of unequal relations equals the total number of relations minus the number of equal relations.

${ }^{25}$ See Mosquera (2017b), p. 186.

${ }^{26}$ Moreover, of the 1,000 individuals in $Z^{\prime}, 949$ individuals are subject to at least one relation of inequality greater than 50 (which represents $94.9 \%$ of population $Z^{\prime}$ ) as opposed to 1 individual in $\mathrm{Z}$ (which represents only $0.1 \%$ of the population).

${ }^{27}$ See Mosquera (2017b), p. 186.

${ }^{28}$ Segall (2016: 76, last emphasis added).

${ }^{29}$ For just one example of the latter, see Arrhenius (2013: 85-86), where he discusses how to weigh the goodness of an increase in equal relations against an increase in slightly unequal relations. There are many more examples.

${ }^{30}$ Arrhenius (2013: 79). 
depends on the gap between the best and worst-off in the population. On this view, the egalitarian value doesn't change with an increase in the number of pairwise inequalities as long as the distance between the best and worst-off is preserved (by, for example, adding more worse off people). Likewise, the view that Segall ascribes to Arrhenius above, which ignores the size of the inequalities and only counts the number of unequal pairs, ${ }^{31}$ is actually incompatible with negative and positive egalitarianism. $^{32}$

\section{Class division}

Are there any other reasons to $\operatorname{rank} \mathrm{Z}$ as worse that $\mathrm{Z}^{\prime}$ with respect to egalitarian concerns? Segall (2016) again hints at the putative badness of the isolation of a single worse-off individual in a society (see quote in the preceding section). But analogously to our reasoning above regarding the case in figure 1, this putative badness can hardly outweigh the greater number and the greater size of the inequalities in $Z^{\prime}$ as compared to $\mathrm{Z}^{33}$

More interestingly, one might argue that $\mathrm{Z}$ is worse than $\mathrm{Z}^{\prime}$ regarding another egalitarian consideration: class division. In $Z$, there is a clear class division with one group of better-off people and another group with (only) one worst-off person. In $Z^{\prime}$, one might argue, there is no clear class division since there is only a small difference in wellbeing between each adjacent individual (see figure 2). Hence, there seem to be no distinct upper or lower classes in $Z^{\prime}$, or so the argument goes. ${ }^{34}$

Several things can be said in response to this argument. As with the claim regarding the badness of isolation, this could be taken as an empirical claim regarding the negative welfare effects of class division. It has been shown that there are positive correlations between different positions in a social hierarchy and the degree of mental and physical health, the degree of happiness, the rate of deaths, etc., of that position in the hierarchy. ${ }^{35}$ As true as that is, this version of the objection misses its target in the same way as the 'empirical' version of the isolation argument above, since any such effects on people's welfare are already taken into account in the figure.

\footnotetext{
${ }^{31}$ Mosquera labels this kind of view 'Aggregative pairwise inequality' in Mosquera (2017b: 149).

${ }^{32}$ This feature makes positive and negative egalitarianism unsuitable as a general characterisation of all egalitarian views and shows that they are substantial positions. For the former we would need something weaker not to exclude positions such as the range measure. Indeed, negative egalitarianism rules out Gini in different-number cases since, as shown by Arrhenius (2016), according to Gini, a mere increase in unequal relations by adding more individuals to the population might sometimes improve the situation in respect to inequality. Another principle that negative egalitarianism rules out is Temkin's BOP (the Relative to the best-off person view of complaints) in combination with his Additive principle of equality (Temkin (1993) ). According to this combined principle, all the individuals but the very best-off have a complaint and the badness of the inequality of a population is equivalent to the aggregated number of complaints of all but the very best-off in that population. A principle like this, unlike negative egalitarianism, is insensitive to the addition of better-off people (i.e. adding more people at the level of the better-off doesn't increase the badness of inequality) since it only looks at the difference with the best-off person, irrespective of the number of people who happen to be at this level. Although a general characterisation of all egalitarian views is an interesting question, we set this issue aside for now.

${ }^{33}$ Moreover, one might argue that there is isolation in population $Z^{\prime}$ too since no one has the same level of welfare. On the other hand, the badness of isolation might depend on how big the welfare difference is. We shall not pursue this line of argument further here.

${ }^{34}$ As suggested by Shlomi Segall in personal communication.

${ }^{35}$ See e.g. Wilkinson \& Pickett (2009). Thanks to an anonymous reviewer for stressing this point.
} 
More interestingly, whether $\mathrm{Z}$ and $\mathrm{Z}^{\prime}$ can be interpreted as containing a class division depends on the conception of welfare involved in the case or whether an index or proxy for welfare is used. For some conceptions or proxies of welfare, welfare differences might very well track class differences, understood in terms of social or economic status, the most common elements used to define class. ${ }^{36}$ For others, there is no clear connection. For example, conceptions or proxies of welfare such as income and wealth are likely to track class differences.

On the other hand, with conceptions of welfare such as experientialist, desire satisfaction, and objective lists theories the connection between welfare and class is weaker. For example, given these conceptions, the reasons why the welfare of individual 1 in $\mathrm{Z}$ is significantly lower than the others' may be due to a painful medical condition that others in that population don't suffer, but she might otherwise enjoy high social and economic status. She might, for example, be a member of a wealthy aristocratic family despite suffering from such a painful condition. Such interpretations are not ruled out by the very abstract description of the case that we have provided here. In conclusion, these conceptions of welfare differences don't always track class differences.

The notion of welfare used in this article is a broad one and is compatible with experientialist, desire satisfaction, and objective list theories. ${ }^{37}$ Given that we use a broad notion of welfare, one cannot infer from the description of $\mathrm{Z}$ and $\mathrm{Z}^{\prime}$ that those populations contain any particular social stratification, or that the individuals involved in those populations belong to any particular class. ${ }^{38}$

However, let's for the sake of the argument accept that $\mathrm{Z}$ and $\mathrm{Z}^{\prime}$ can be compared in terms of class division. Even so, it would not be true that $Z$ is worse than $Z^{\prime}$ from the point of view of class division. This becomes clearer with the following representation of the case:

Although the difference in welfare between each pair of adjacent people in $Z^{\prime}$ is small, by looking at figure 4 we can clearly see that there are groups whose individuals are much better off than the individuals in other groups, such as the people in the 1st and 2 nd classes as compared to the people in the 3rd class. Indeed, we can imagine that these groups represent the lower class, middle class, and the upper class in that population. And the fact that there are people in between these three classes who cannot be clearly classified as belonging to any of these classes doesn't refute the existence of this class division in $Z^{\prime}$.

Perhaps one might object here that it is not clear how the grouping into classes would be made in a society that looked like $\mathrm{Z}^{\prime}$, or that there is no salient way of doing so, while such a grouping is rather natural in $\mathrm{Z}$. As true as this might be, it is of no normative significance. That there are many ways of grouping people doesn't show that there wouldn't be some ways (or at least one) that are more relevant from

\footnotetext{
${ }^{36}$ Notice that there isn't consensus on what is the right definition of 'class'. While contemporary political scientists tend to identify class with income or wealth (i.e. they refer to class differences mainly as income or wealth differences), sociologists tend to include other elements in the definition, such as educational background, parental background, and/or the relation to the means of production. We would like to thank Malcolm Fairbrother, Chandra Kumar, and Stefan Svallfors for a discussion of this issue.

${ }^{37}$ For experientialist theories, see e.g. Sumner (1996), Feldman (1997), Feldman (2004), and Tännsjö (1998). For desire theories, see e.g. Barry (1989), Bykvist (1998), Griffin (1986), and Hare (1981). For objective list theories, see e.g. Braybrooke (1987), Hurka (1993), Rawls (1971), and Sen (1980), (1992a), (1993).

${ }^{38}$ One might also object to the conceptual possibility that a single person can constitute a 'class' (the single person at low level in Z). We shall not pursue this line of argument further here.
} 


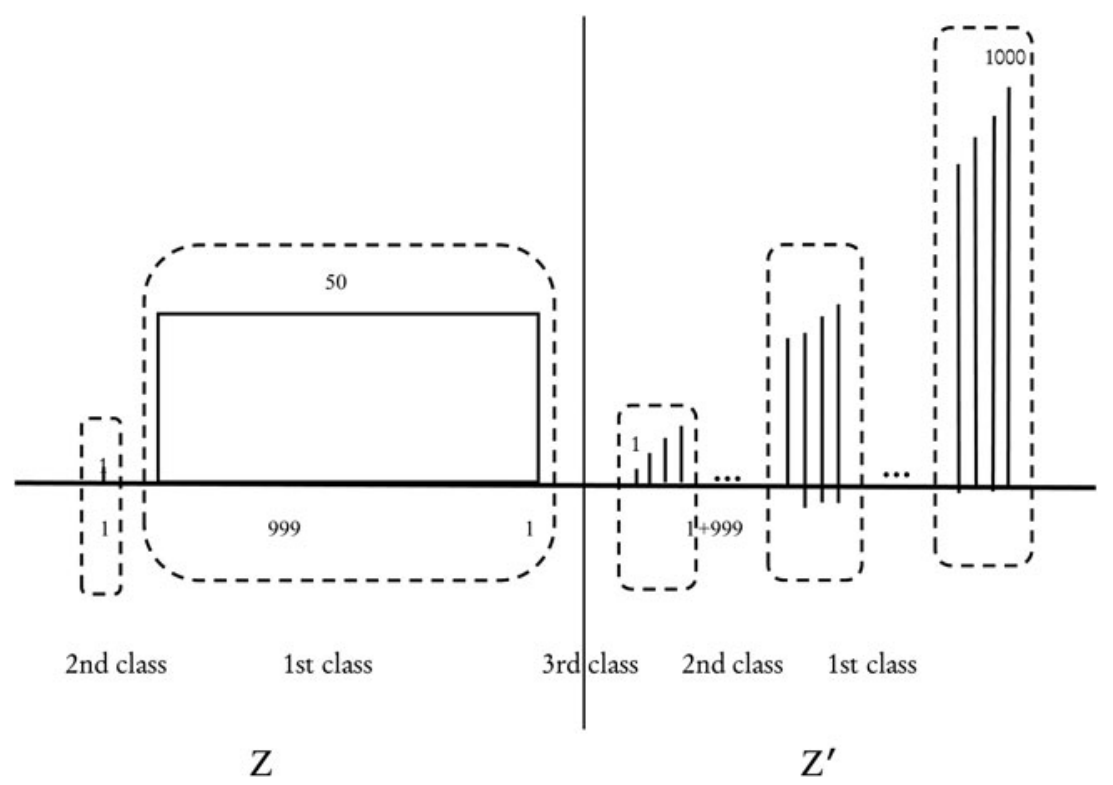

Figure 4. Possible class divisions in $Z$ and $Z^{\prime}$.

the perspective of egalitarian concerns. And our point is that there is at least one such grouping that shows that $\mathrm{Z}^{\prime}$ is also a class society. Hence, it is not the case that $\mathrm{Z}$ is worse than $Z^{\prime}$ regarding this egalitarian consideration.

\section{Perfect and rough equality}

At this point, one might worry that the question of whether equality can have positive value is only interesting if people can in fact have exactly the same level of the currency that ought to be distributed equally, in a wide range of cases. For example, in realistic cases, perfect equality of welfare will almost never hold, or so one might argue. So, if welfare is the correct egalitarian currency, and if it is so rare that two or more individuals will be perfectly equal in respect to welfare, what is then the point of determining the positive value of equality? Doesn't this make the focus on equality, albeit theoretically interesting, practically irrelevant? Larry Temkin has recently put forward this argument. $^{39}$

There are at least two answers to Temkin's worry. Firstly, whether people can achieve perfect equality depends on how the egalitarian currency is specified. In realistic cases, perfect (formal) legal equality (e.g. the same laws for different ethnic groups, or genderneutral laws) is arguably much easier to obtain than perfect equality of welfare and this equality has already been achieved among large groups of people in many countries, or so one might argue. Hence, if one cares about legal equality, then the positive value of equality is practically relevant. Moreover, one could care about inequality and equality for several currencies at the same time, for example both legal equality and equality of

\footnotetext{
${ }^{39}$ In personal communication.
} 
welfare. In that case, even if perfect equality of welfare is rare, the positive value of equality is still practically relevant since perfect legal equality isn't rare.

Secondly, Arrhenius (2013) has suggested a version of positive egalitarianism in terms of what he calls 'rough equality'. Small differences in welfare, that is, small inequalities, can also be described as 'rough equalities'. One might then ask whether it is only perfectly equal relations that have positive value or whether this is also true of roughly equal relations. A promising idea is that inequality has negative value when the inequality is sufficiently big ('strict inequality' as we can call it), but when it gets smaller we reach the border for rough equality, which is of neutral value, and when the welfare difference gets even smaller, rough equality has positive value, and this value increases the closer we get to perfect equality. So, for example, $\langle 5,10\rangle$ might have negative value from an egalitarian perspective; $<8,10>$ neutral value, since we have reached the border for rough equality; $\langle 9,10\rangle$ positive value since we are getting close to perfect equality; and lastly $\langle 10,10\rangle$ has maximal positive value regarding egalitarian concerns.

We can formulate rough positive egalitarianism in the following way:

Rough positive egalitarianism: The egalitarian value of a population is a strictly decreasing function of pairwise relations of strict inequality and a strictly increasing function of pairwise relations of rough and perfect equality. ${ }^{40}$

This view, we suggest, can accommodate the worry raised by Temkin. Rough positive egalitarianism captures the idea that individuals don't need to be at the exact same level of welfare in order for there to be some positive value of equality in the relation that holds between them. There is a point at which individuals' welfare is close enough to each other's to instantiate this value: when they are sufficiently equally well off so that they can, so to speak, look each other in the eyes as equals. This view, we believe, fits the way in which people think and talk about equality. When lay people and policy makers express pro-attitudes and make claims regarding equality, they rarely have in mind perfect equality but rather rough equality. Real policies with an egalitarian agenda seldom aim at the achievement of perfect equality of the welfare of the citizens in a given country (although they might do so when it comes to other currencies, like the achievement of perfect legal equality).

Again, this conception of equality is analogous to how the value of desert has been conceptualised. If someone deserves a certain amount of some good, it is not only good that the person receives exactly what she deserves, it is also good, although less so, that she receives close to what she deserves. A mismatch between desert and receipt is only bad when the difference between what is deserved and what is being received is sufficiently big. ${ }^{41}$

\footnotetext{
${ }^{40}$ Cf. Arrhenius (2013), p. 89.

${ }^{41}$ See, e.g. Feldman (1995a), (1995b), (1997), Arrhenius (2003a), (2006), (2007). The idea of rough equality also has an interesting connection to John Rawls' (1982) view that we have reasons to prefer metrics of interpersonal comparison such that it is publicly verifiable whether two individuals stand in relations to equality to each other. His choice of primary goods over welfare in the context of public deliberation was a response to this reason. It is easier to publicly verify whether two individuals have roughly the same primary goods than it is to verify whether they are equal in terms of, say, hedonistic welfare. Likewise, rough equality is easier to publicly verify than perfect equality for most currencies of equality, and might be a way of meeting Rawls' public verifiability criterion without shifting to primary good as the currency of equality. This is an interesting possibility that we hope to address further in the future.
} 
Segall argues that there is a tension between positive egalitarianism and rough positive egalitarianism. It involves population $\mathrm{Z}$ and $\mathrm{Z}^{\prime}$ from the progression case discussed in the previous sections. According to Segall, rough positive egalitarianism judges $Z$ as worse than $Z^{\prime}$. And this, Segall argues, contradicts the ranking of positive egalitarianism for these populations:

There are reasons to think that Arrhenius himself ought to also be committed to the view that $Z^{\prime}$ is better than $Z$ with respect to equality. When considering the badness of small inequalities he says that a promising approach is 'that inequality has a negative value when the inequality is sufficiently big but, when it gets smaller, we have rough equality that is of neutral value'.

And he continues, referring to the supposed implications of rough positive egalitarianism:

On this reading [of Rough Equality], in $\mathrm{Z}$ we have 999 relations of sufficiently big inequalities and hence negative value, whereas in $Z^{\prime}$ we have almost half a million relations of small inequalities and hence neutral value. So it seems that even on Arrhenius' intuition $Z^{\prime}$ is better than $Z$, even though the former contains no relations of equality. ${ }^{42}$

It is important to note, though, that it is not the case that 'in $\mathrm{Z}^{\prime}$ ' we have almost half a million relations of small inequalities and hence neutral value'. Certainly, there are small inequalities between adjacent or close pairs in the progression and they might be of neutral value or even of positive value according to rough positive egalitarianism. The latter would count in favour of $Z^{\prime}$ being better than $Z$ from an egalitarian perspective. But, as we pointed out above, the vast majority of the relations of inequality in $Z^{\prime}$ involve big and greater gaps than the inequalities in $\mathrm{Z}$. Hence, we can conclude that also for those who adhere to rough positive egalitarianism, there are very strong reasons to hold that $Z^{\prime}$ is worse than $Z$ with respect to egalitarian considerations. The same reasons that support the ranking provided by negative and positive egalitarians also apply for rough positive egalitarianism. ${ }^{43}$

We are grateful to an anonymous reviewer for suggesting this connection between rough equality and Rawls' theory of justice.

${ }^{42}$ Segall (2016), p. 76, fn. 7.

${ }^{43}$ One might worry that rough positive egalitarianism introduces a new problem as compared to positive and negative egalitarianism, namely an arbitrary cut-off point at which inequalities stop having negative value and start having neutral or positive values. It is true that such a cut-off point needs to be specified but it doesn't follow that it has to be arbitrary and it isn't a problem specific to this theory. Cut-off points in value are a common feature of many axiological theories, if not all of them. Critical level utilitarianism will have to specify its critical level; desert theories have to determine which level of welfare people deserve and how to value mismatches between desert and receipt; prioritarianism has to determine the priority weights assigned to different levels of welfare, and sufficientarianism has to determine at which level the sufficiency threshold should be drawn, to just take some well-known examples. Even positive and negative egalitarianism have to determine what counts as being perfectly equal and the weight to be given to different inequalities (e.g. inequalities at different levels) and how to aggregate them. So the so-called 'arbitrariness objection' is rather a general problem in axiology and nothing specific to rough positive egalitarianism. Such cut-off points have to be determined by our intuitions over particular cases and methodological concerns such as simplicity and coherence in a wide reflective equilibrium. Moreover, such cut-off points might 


\section{The repugnant equality objection}

Finally, one may think that upholding to a view like positive egalitarianism, which attributes positive value to relations of equality, might lead to a version of Derek Parfit's famous repugnant conclusion which, following Mosquera (2017b), we will call repugnant equality:

Repugnant equality: For any population consisting of people enjoying the same very high positive welfare, there is a better population with respect to egalitarian concerns in which everyone has the same very low positive welfare. ${ }^{44}$

According to Segall, positive egalitarianism 'probably' ranks $\mathrm{Z}$ as better than A from the point of view of equality even when the lives in $Z$ are barely worth living since $Z$ 'contains many more relations of equality' as compared to A. ${ }^{45}$ Hence, positive egalitarianism implies that $\mathrm{Z}$ is better than $\mathrm{A}$ in one respect, namely in respect of egalitarian concerns, that is, repugnant equality. He finds this implication counterintuitive. ${ }^{46}$

Repugnant equality is a variation of Derek Parfit's well-known repugnant conclusion. ${ }^{47}$ It is also structurally analogous to the levelling down objection in the following sense. According to the levelling down objection, one cannot make a situation better in any respect by only decreasing the welfare of the better-off (to the same level as the worse-off). Many conceptions of the value of equality, like those discussed here, have this implication, but, along with many egalitarians, we don't find the objection persuasive. It would be a different matter if a theory implied that it was all things considered better to level down, which of course would be highly counterintuitive. ${ }^{48}$ Likewise, it doesn't follow from repugnant equality that one has to accept that $\mathrm{Z}$ is better than $\mathrm{A}$ all things considered, but only that $\mathrm{Z}$ is better in one respect. We reject the former value judgement but, pace Segall, don't find the latter one counterintuitive.

Actually, the very idea that it can be a decisive argument against a theory that it implies that an outcome is better or worse in one respect is often question-begging. The reason is that this kind of objection can be launched against any theory according to which the value can vary in at least two dimensions. This is, however, an unsurprising feature of such theories. Take hedonistic total utilitarianism, according to which the value of an outcome is determined by the total sum of pleasure over pain, as an example. Consider the value of adding a person with negative lifetime total sum of pleasure and pain. Of course, this would be all things considered bad according to hedonistic total utilitarianism. However, assume that this life involves one minute of pleasure in addition to all the pain and suffering. Then it is true that in one respect, from the perspective of hedonistic total utilitarianism, it is good to add this life because one minute of pleasure is added to the world. Clearly, this isn't much of an objection to

very well be imprecise and vague, which can be handled by some of the standard approaches to vagueness, such as the supervaluationist account. Thanks to an anonymous reviewer for raising this issue.

${ }^{44}$ Our formulation. See Segall (2016) and Mosquera (2017b) for a similar formulation.

${ }^{45}$ Segall (2016), p. 77.

${ }^{46}$ Segall (2016), p. 77.

${ }^{47}$ See Parfit (1984), p. 388

${ }^{48}$ Cf. Arrhenius (2013), p. 92. Segall (2016), p. 78, agrees with this: 'Levelling down would bring about equality. This is, for sure, a defeasible reason, but it's a reason nevertheless.' He also suggests, correctly in our view, that a theory 'may judge a scenario to make an outcome better (in one respect), even when it's better for no one, is not self-evidently problematic' (Segall (2016), p. 350). 


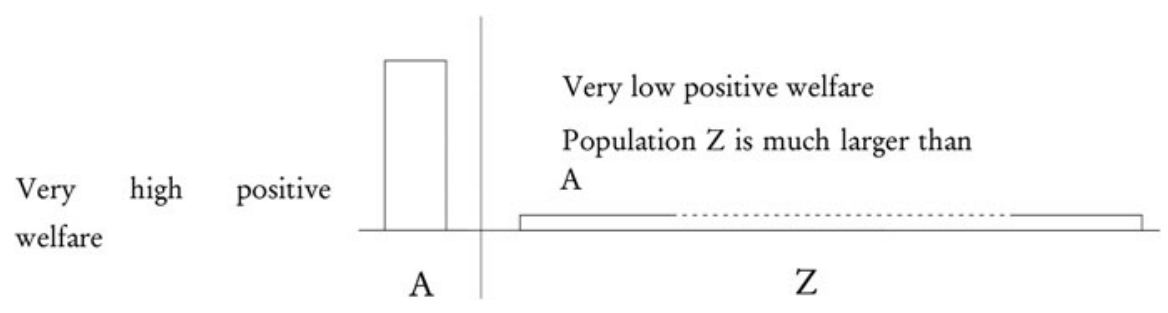

Figure 5. Repugnant equality.

this version of utilitarianism. Likewise for the levelling down objection against egalitarian theories in general and the 'in-one-respect-better objections' raised above by Segall against positive egalitarianism. There is nothing counterintuitive about this feature of multidimensional axiologies for which outcomes can be both good and bad in different respects.

Moreover, positive egalitarians are not even committed to ranking $\mathrm{Z}$ as better than $\mathrm{A}$ in respect of egalitarian concerns, that is, they are not committed to repugnant equality. As Arrhenius has pointed out, 'how valuable equal relations are might arguably depend on the level of welfare involved'. ${ }^{49}$ This is analogous to the commonly held belief among egalitarians that the negative value of unequal relations partly depends on the welfare levels of the involved individuals such that inequalities at low levels are worse than inequalities at high levels. Hence, it is open to positive egalitarians to give different values to equal relationships at different welfare levels such that, for example, no number of equal relationships at a very low positive welfare level is better with regard to egalitarian concerns than a certain number of equal relationships at a very high positive welfare level. This could, to take a simple example, be achieved by aggregating the value of equal relationships at high welfare levels linearly while the value of equal relationships at low positive welfare levels is aggregated by a strictly concave function with an upper limit. ${ }^{50}$ Of course, there are more elaborate ways of developing this idea, for example, by having concave functions with different limits for each level of welfare. Hence, pace Segall, positive egalitarianism doesn't imply repugnant equality. ${ }^{51}$

Similar considerations hold for the following putative objection to positive egalitarianism raised first by Arrhenius:

if one does assign some small positive value to such relations of equality, then one would have to accept an implication akin to the levelling down objection: Adding people with negative welfare to a population might make it in one respect better,

\footnotetext{
${ }^{49}$ Arrhenius (2013), p. 89.

${ }^{50}$ This is of course analogous to how one can avoid Parfit's repugnant conclusion even if one is committed to the positive contributive value of lives enjoying positive welfare. See e.g. Arrhenius (2000a), (2005); Arrhenius, Ryberg, \& Tännsjö (2014). Of course, any theory of this sort (and many others, e.g. prioritarianism) faces the epistemic problem of how to determine the right shape of the concave function. This problem has no relevance for our discussion here, however.

${ }^{51} \mathrm{~A}$ broader version of positive egalitarianism according to which the egalitarian value is just an increasing function (instead of a strictly increasing function) of equal relations opens up another way of avoiding repugnant equality since it's compatible with a reachable upper limit to the total value of equal relations that has already been reached in A. Hence, this view would rank $\mathrm{A}$ and $\mathrm{Z}$ as equally good regarding egalitarian concerns. However, we don't find this view compelling.
} 
although not all things considered better, since it might increase the value of equality in the population. ${ }^{52}$

As with repugnant equality and the levelling down objection, there are two possible answers here. One can bite the - in our view just imaginary - bullet and accept a defeasible egalitarian reason to add equal people with negative welfare. Or, in extending positive egalitarianism to negative welfare levels, one can assign neutral value to equal relationships of negative welfare. In such cases, it wouldn't follow that adding people with negative welfare to a population would make such a population in one respect better. We prefer the first option since we are not persuaded by the levelling down objection and since we find it hard to motivate the second option. ${ }^{53}$

A related and interesting objection to positive egalitarianism (which also could be directed at negative egalitarianism, mutatis mutandis) has to do with its impersonal nature'. The idea is that it is too concerned with making equal people instead of making people equal, to paraphrase Jan Narveson's famous slogan (in analogy to the criticism of total utilitarianism implying that we should make happy people instead of making people happy). ${ }^{54}$ As we have stated of positive egalitarianism, it is true that it isn't a so-called person-affecting theory: it disregards modal and temporal factors in its evaluation of outcomes. ${ }^{55}$ However, one could formulate person-affecting versions of positive egalitarianism, along the lines of how people have tried to formulate person-affecting versions of total utilitarianism. This latter project has, however, proved to be unsuccessful. The person-affecting intuition is very attractive but all efforts to incorporate it have yielded theories with strongly counterintuitive consequences. ${ }^{56}$ It is likely that the project of formulating a person-affecting version of positive or negative egalitarianism would meet the same fate, we surmise, so we shall not pursue it further here. ${ }^{57}$

\footnotetext{
${ }^{52}$ Arrhenius (2013), p. 89. It's repeated as an objection in Segall (2016), p. 78 and Segall (2019), pp. 3-10.

${ }^{53}$ The motivating idea could be that equality only has value when it's equality of something good. This seems doubtful, however, since we seem to value equality among bad things too, such as carrying burdens equally or equal punishment for similar crimes.

${ }^{54}$ 'We are in favor of making people happy, but neutral about making happy people' (Narveson (1973), p. 80).

${ }^{55}$ For a discussion of the many different meanings of a person-affecting theory, see Arrhenius (2000b), (2003b), (forthcoming).

${ }^{56}$ See Arrhenius (2000b), (2003b), (2015), (forthcoming). Cf. McMahan (2002), p. 300: '[T] he view that there is no strong moral reason to cause a person to exist just because his life would contain much good ... is deeply intuitive and probably impossible to dislodge'.

${ }^{57}$ Another intuitively very attractive idea in population ethics is the Asymmetry according to which we have no moral reasons for or against creating people with positive welfare stemming from the welfare these people would enjoy, but, on the other hand, we have moral reasons against creating people with negative welfare stemming from the negative welfare these people would suffer (see references in the above footnote). Likewise, one could argue, we have no moral reasons for or against creating people with equal relations stemming from the value of those relations, but, on the other hand, we have moral reasons against creating people with unequal relations stemming from the negative value of those equal relations (see Mosquera (2017b), pp. 187-88). The asymmetry is a powerful intuition but has been shown to have very counterintuitive implications in its strong version and it has been rather convincingly argued that only a weaker version can be defended (see e.g. Arrhenius (2000b), (2003b), (2015), (forthcoming) ): We might have moral reasons for creating people with positive welfare stemming from the welfare these people would enjoy but these reasons are never decisive in themselves (they can always be overridden by some other consideration such as, for example, parental autonomy); we always have moral reasons against creating people with negative welfare stemming from the negative welfare these people would suffer, and these reasons are
} 


\section{Conclusion}

Positive egalitarianism is the view that ascribes positive value to relations of equality in addition to negative value to relations of inequality. In this article, we have developed this view further and tried to show how some of the recently presented criticisms against it are unpersuasive and don't give us decisive or new reasons to reject it. Moreover, positive egalitarianism adds a new set of exciting issues to the traditional discussion of egalitarianism which deserve further attention and development. Of course, there are many interesting but unresolved issues that remain for positive egalitarians to address, to which we hope to return in future work. ${ }^{58}$

\section{References}

Arneson, R. J. (1989). Equality and Equal Opportunity for Welfare. Philosophical Studies, 56(1), 77-93.

Arrhenius, G. (2000a). An Impossibility Theorem for Welfarist Axiologies. Economics and Philosophy, 16(2), 247-66.

Arrhenius, G. (2000b). Future Generations: A Challenge for Moral Theory, <http://www.diva-portal.org/ smash/record.jsf?pid=diva2:170236>.

Arrhenius, G. (2003a). Feldman's Desert-Adjusted Utilitarianism and Population Ethics. Utilitas, 5(2), $225-36$.

Arrhenius, G. (2003b). The Person-Affecting Restriction Comparativism and the Moral Status of Potential People. Ethical Perspectives, 10(3-4), 185-95.

Arrhenius, G. (2005). Superiority in Value. Philosophical Studies, 123(1/2), 97-114, <https://doi.org/10. 1007/s11098-004-5223-0>.

Arrhenius, G. (2006). Desert as Fit: An Axiomatic Analysis. In K. McDaniel, J. R. Raibley, R. Feldman, \& M. J. Zimmerman (eds), The Good, the Right, Life And Death: Essays in Honor of Fred Feldman (pp. 3-17). Aldershot, England; Burlington, VT: Ashgate Pub Co.

Arrhenius, G. (2007). Meritarian Axiologies and Distributive Justice. In T. Rønnow-Rasmussen, B. Petersson, J. Josefsson, \& D. Egonsson (eds), Hommage à Wlodek. Philosophical Papers Dedicated to Wlodek Rabinowicz (pp. 1-43). Stockholm University.

Arrhenius, G. (2009). Egalitarianism and Population Change. In A. Gosseries \& L. Meyer (eds), Intergenerational Justice (1st Edition, pp. 325-49). Oxford: Oxford University Press.

Arrhenius, G. (2013). Egalitarian Concerns and Population Change. In O. Frithjof Norheim, N. Eyal, S. A. Hurst, \& D. Wikler (eds), Inequalities in Health: Concepts, Measures, and Ethics (pp. 74-91). Oxford: Oxford University Press.

Arrhenius, G. (2015). The Affirmative Answer to the Existential Question and the Person Affecting Restriction. In Weighing and Reasoning: Themes from the Philosophy of John Broome (pp. 110-125). Oxford: Oxford University Press.

Arrhenius, G. (2016). Inequality and Population Change. mimeo, Institute for Futures Studies, Stockholm. Arrhenius, G. (2019). Population Change, Poverty, Health, and Inequality Measures. Institute for Futures Studies.

often decisive (can seldom be overridden by other considerations such as parental autonomy). Such an asymmetry for equality, mutatis mutandis, would be compatible with positive egalitarianism and preserve what is important with the intuition we think. To fully explore this issue has to wait to another occasion, however. We are grateful to an anonymous referee for bringing it up.

${ }^{58}$ We would like to thank Andrea Asker, Paul Bowman, Krister Bykvist, Tim Campbell, Nils Holtug, Kasper Lippert-Rasmussen, Shlomi Segall, Orri Stefánsson, and Folke Tersman for very helpful discussions. Thanks also to the audiences at the Society for Applied Philosophy Conference, Copenhagen, June 2017; the workshop Ethics and Political Philosophy, University of Copenhagen, October 2017; the Institute for Futures Studies' PPE-seminar, September 2017; and the higher seminar at the Department of Philosophy, Uppsala University, October 2017, and two anonymous reviewers for useful questions and comments. Financial support from the Swedish Research Council and Riksbankens Jubileumsfond is gratefully acknowledged. 
Arrhenius, G. (forthcoming). Population Ethics: The Challenge of Future Generations. Oxford: Oxford University Press.

Arrhenius, G., Ryberg, J., \& Tännsjö, T. (2014). The Repugnant Conclusion. In E. N. Zalta (ed.), The Stanford Encyclopedia of Philosophy (Spring 2014), <http://plato.stanford.edu/archives/spr2014/entries/ repugnant-conclusion/>.

Barry, B. (1989). Utilitarianism and Preference Change. Utilitas, 1(02), 278-82, <https://doi.org/10.1017/ S0953820800000273>.

Bommier, A., Lanz, B., \& Zuber, S. (2015). Models-as-usual for Unusual Risks? On the Value of catastrophic Climate Change. Journal of Envrionmental Economics and Management, 74, 1-22.

Bosmans, K., Decancq, K., \& Decoster, A. (2014). The Relativity of Decreasing Inequality Between Countries. Economica, LSE, 81(322), 276-92, <https://doi.org/10.1111/ecca.12059>.

Braybrooke, D. (1987). Meeting Needs Princeton, NJ: Princeton University Press.

Broome, J. (1999). Ethics out of Economics. Cambridge: Cambridge University Press.

Broome, J. (2004). Weighing Lives. Oxford: Oxford University Press.

Bykvist, K. (1998). Changing Preferences: A Study in Preferentialism. Uppsala: Acta Universitatis Upsaliensis.

Carleton, T., Delgado, M., Greenstone, M., Houser, T., Hsiang, S., Hultgren, A., . . Zhang, A. (2019). Valuing the Global Mortality Consequences of Climate Change Accounting for Adaptation Costs and Benefits, <https://bfi.uchicago.edu/working-paper/valuing-the-global-mortality-consequences-of-climatechange-accounting-for-adaptation-costs-and-benefits/>.

Cohen, G. A. (1989). On the Currency of Egalitarian Justice. Ethics, 99(4), 906-44.

Cohen, G. A. (1993). Equality or What? On Welfare, Goods and Capabilities. In A. Sen \& M. C. Nussbaum (eds), The Quality of Life. Oxford: Clarendon Press.

Crisp, R. (1997). Routledge Philosophy Guidebook to Mill on Utilitarianism. London: Routledge.

Dworkin, R. (1981a). What is Equality? Part 1: Equality of Welfare. Philosophy \& Public Affairs, 10(3), $185-246$.

Dworkin, R. (1981b). What is Equality? Part 2: Equality of Resources. Philosophy \& Public Affairs, 10(4), 283-345.

Dworkin, R. (2000). Sovereign Virtue: The Theory and Practice of Equality. Cambridge, MA: Harvard University Press.

Feldman, F. (1995a). Adjusting Utility for Justice: A Consequentialist Reply to the Objection from Justice. Philosophy and Phenomenological Research, 55(3), 567-85.

Feldman, F. (1995b). Justice, Desert, and the Repugnant Conclusion. Utilitas, 7(02), 189-206.

Feldman, F. (1997). Utilitarianism, Hedonism, and Desert: Essays in Moral Philosophy. Cambridge: Cambridge University Press.

Feldman, F. (2004). Pleasure and the Good Life: Concerning the Nature, Varieties, and Plausibility of Hedonism. Oxford: Oxford University Press.

Geruso, M., \& Spears, D. (2018). Heat, Humidity, and Infant Mortality in the Developing World. IZA Institute of Labor Economics, IZA DP No. 11717.

Griffin, J. (1986). Well-Being: Its Meaning, Measurement, and Moral Importance. Oxford: Clarendon Press.

Hales, S., Kovats, S., Lloyd, S., \& Campbell-Lendrum, D. (2014). Quantitative Risk Assessment of the Effects of Climate Change on Selected Causes of Death, 2030s and 2050s. Geneva: WHO.

Hare, R. M. (1981). Moral thinking: Its Levels, Method, and Point. Oxford: Clarendon.

Hurka, T. (1993). Perfectionism. New York: Oxford University Press.

Kawchuk, R. (1996a). (In)Equality. Dept. of Philosophy, University of Calgary.

Kawchuk, R. (1996b). (In)Equality, <http://dx.doi.org/10.11575/PRISM/16631>.

McMahan, J. (2002). The Ethics of Killing: Problems at the Margins of Life. New York: Oxford University Press.

Mejean, A., Pottier, A., Zuber, S., \& Fleurbaey, M. (2017). Intergenerational Equity under Catastrophic Climate Change. Documents de Travail Du Centre d'Economie de La Sorbonne.

Mosquera, J. (2017a). An Egalitarian Argument against Reducing Deprivation. Ethical Theory Moral Practice, 20(5), 957-68.

Mosquera, J. (2017b). Disability, Equality, and Future Generations. PhD thesis, University of Reading.

Narveson, J. (1973). Moral Problems of Population. The Monist, 57(1), 62-86, <https://doi.org/10.5840/ monist197357134>. 
Nielsen, K. (1996). Radical Egalitarianism Revisited: On Going Beyond The Difference Principle. Windsor Yearbook of Access to Justice, 15, 121-58.

Oddie, G. (2005). Value, Reality and Desire. Oxford: Oxford University Press.

Parfit, D. (1984). Reasons and Persons. Oxford: Clarendon.

Parfit, D. (1986). Overpopulation and the Quality of Life. In P. Singer (ed.), Applied Ethics (pp. 145-64). Oxford: New York: Oxford University Press.

Persson, I. (2001). Equality, Priority and Person-Affecting Value. Ethical Theory and Moral Practice, 4(1), 23-39.

Rabinowicz, W. (2003). The Size of Inequality and its Badness: Some Reflections Around Temkin's Inequality. Theoria, 69(1-2), 60-84.

Rawls, J. (1971). A Theory of Justice. Cambridge, MA: Belknap Press.

Rawls, J. (1982). Social Unity and Primary Goods. In B. Williams \& A. Sen, Utilitarianism and Beyond (pp. 159-85). Cambridge: Cambridge University Press.

Segall, S. (2016). Why Inequality Matters: Luck Egalitarianism, its Meaning and Value. Cambridge: Cambridge University Press.

Segall, S. (2019). Why We Should be Negative about Positive Egalitarianism. Utilitas, 1-17, <https://doi. org/10.1017/S0953820819000219>.

Sen, A. (1980). Equality of What? In S. McMurrin (ed.), The Tanner Lectures on Human Values. Cambridge: Cambridge University Press.

Sen, A. (1992a). Inequality Re-examined (Reprint edition). New York: Harvard University Press.

Sen, A. (1992b). Justice and Capability. In Inequality Reexamined (pp. 73-101). New York: Russell Sage Foundation; Harvard University Press.

Sen, A. (1993). Capability and Well-Being. In A. Sen \& M. C. Nussbaum (eds), The Quality of Life. Oxford: Clarendon Press.

Sumner, L. W. (1996). Welfare, Happiness, and Ethics. New York: Clarendon Press.

Tännsjö, T. (1998). Utilitarianism and Common Sense Morality. In Hedonistic Utilitarianism (pp. 153-71). Edinburgh: Edinburgh University Press.

Temkin, L. S. (1993). Inequality. New York: Oxford University Press.

Wilkinson, R. G., \& Pickett, K. (2009). The Spirit Level: Why Greater Equality Makes Societies Stronger. New York, NY: Bloomsbury Press.

Cite this article: Arrhenius G, Mosquera J (2022). Positive Egalitarianism Reconsidered. Utilitas 34, 19-38. https://doi.org/10.1017/S0953820819000566 